\title{
The effect of depression status change on daily cigarette smoking amount according to sex: an eleven-year follow up study of the Korea Welfare Panel Study
}

Soo Hyun Kang ${ }^{1,2}$, Wonjeong Jeong ${ }^{1,2}$, Sung-In Jang ${ }^{2,3}$ and Eun-Cheol Park ${ }^{2,3^{*}}$ (i)

\begin{abstract}
Background: In the past decade, the Korean smoking rate has only decreased by $3 \%$, despite several smoking control policies. There is a need for such policies to take smokers' psychological characteristics into account. Depression is a well-known contributor to failed smoking cessation. This study aimed to examine the effect of smokers' depression status changes on their daily cigarette smoking amount (DCA).

Methods: This study used a sample drawn from the Korea Welfare Panel Study (KoWePS) waves 3 (2008) to 13 (2018). The DCA refers to the number of the cigarettes smoked per day at the time of the survey. Depression was measured using an 11-item version of the Center for Epidemiologic Studies Depression Scale (CESD-11). A generalized estimating equation (GEE) model was employed to analyse the effect of change of depression status on DCA.

Results: The 2008 baseline included a total of 1821 participants: 1645 males and 176 females. The Yes $\rightarrow$ No male depression status group had lower DCA $(\beta=-0.631, p$-value $=0.0248)$ than the $\mathrm{No} \rightarrow$ No group. The Yes $\rightarrow$ No male depression status group that began smoking before age 19 had lower DCA ( $\beta=-0.881, p$-value: 0.0089 ) than the No $\rightarrow$ No group that started smoking before 19 .

Conclusions: We found that a change from depressed to non-depressed and non-depressed to depressed status is associated with decreasing and increasing DCA among men, respectively. Also, for smokers who began smoking before 19 years of age, the subgroup that went from depressed to non-depressed had much a lower DCA than general smokers. Thus, when treating people participating in smoking cessation programs, counsellors should check for depression symptoms and encourage individuals to pursue depression treatment simultaneously.
\end{abstract}

Keywords: Depression, Daily cigarette amount, Smoking cessation, Smoking

\footnotetext{
* Correspondence: ecpark@yuhs.ac

${ }^{2}$ Institute of Health Services Research, Yonsei University, Seoul, Republic of

Korea

${ }^{3}$ Department of Preventive Medicine, Yonsei University College of Medicine,

50 Yonsei-ro, Seodaemun-gu, Seoul 03722, Republic of Korea

Full list of author information is available at the end of the article
}

(c) The Author(s). 2021 Open Access This article is licensed under a Creative Commons Attribution 4.0 International License, which permits use, sharing, adaptation, distribution and reproduction in any medium or format, as long as you give appropriate credit to the original author(s) and the source, provide a link to the Creative Commons licence, and indicate if changes were made. The images or other third party material in this article are included in the article's Creative Commons licence, unless indicated otherwise in a credit line to the material. If material is not included in the article's Creative Commons licence and your intended use is not permitted by statutory regulation or exceeds the permitted use, you will need to obtain permission directly from the copyright holder. To view a copy of this licence, visit http://creativecommons.org/licenses/by/4.0/ The Creative Commons Public Domain Dedication waiver (http://creativecommons.org/publicdomain/zero/1.0/) applies to the data made available in this article, unless otherwise stated in a credit line to the data. 


\section{Introduction}

In 2010, 8284 people died of either lung cancer or ischemic heart disease due to ongoing smoking [1]. The Korea National Health and Nutrition Examination Survey (KNHANES) calculated the national smoking rate as $22.3 \%$ in 2017 , with $38.1 \%$ of men falling under the 'current smoker' category. Moreover, the past decade has only seen a $3 \%$ smoking decrease, down from $25.3 \%$.

Since 1982, the Korean government has implemented various smoking control policies, such as regulating cigarette advertisements, adding warning labels to cigarette packs, restricting the sale of cigarettes to adolescents, banning smoking in public places and restaurants, and increasing cigarette prices [2]. Clearly, smoking control policies have not translated to a significant change in the national smoking prevalence. This indicates a need for research and policy development informed by both the sociodemographic and psychological characteristics of smokers.

To predict the success or failure of smoking cessation attempts, researchers have focused on the mitigating role of 'major depressive disorder' or 'depressed mood'. A history of regular smoking was observed more frequently among those who experienced major depressive disorder at some point in their lives than it was among those who had not (non-depressed individuals) [3]. Some studies report that the history of major depressive disorder might imply the failure of smoking cessation $[4,5]$. In addition, the relationship between depressed mood and past major depressive disorder has been supported in many studies on smokers $[6,7]$. On the contrary, attempts to cease smoking, or successful smoking cessation may increase one's risk of experiencing a major depression episode, irrespective of past major depressive disorder history $[8,9]$.

Self-reported daily cigarette amount (DCA) is an important factor used by many studies to assess the level of cigarette dependence. DCA has been used to determine what qualifies as 'heavy' dependence, or categorize those deemed 'hardcore smokers' [10-12]. Some studies have used DCA as a predictor for successful smoking cessation or of attempting cessation. Indeed, Hymowitz reported that individuals with lower daily cigarette consumption levels were statistically significant predictors of smoking cessation [13]. Similarly, Hyland found that individuals who reduced their smoking by more than $50 \%$ over 5 years were 1.7 times more likely to quit smoking in the 13 years after than those who did not [14].

Previous studies also demonstrate the relationship between depression and failure to quit smoking. However, the impact of smokers' depression status change (e.g. from depressed status to non-depressed status) on their DCA has not been adequately assessed. Thus, this study sought to examine the effect of smokers' depression status changes on their DCA.

\section{Methods}

\section{Data and population}

The study used data from the Korea Welfare Panel Study (KoWePS), conducted by the Korea Institute for Health and Social Affairs and Seoul National University. The KoWePS is an annual longitudinal panel survey that was undertaken from 2006 to 2018 . This data is suitable for low-income policies or poverty studies because about $50 \%$ of samples were low income earners with a median income of $60 \%$ or less. This study used a sample drawn from waves 3 (2008) to 13 (2018). The initial 2008 baseline data included 16,613 individuals from 6314 households.

To analyze the effect of smokers' depression status change, we only included currently smoking individuals who are 19 years old and older (excluded $n=13,591$ in 2008). From there, we further excluded 1201 individuals with missing data for used variables in this study. Thus, the 2008 data included a total of 1821 individuals: 1645 males and 176 females.

\section{Measures \\ Daily cigarette smoking amount (DCA)}

The outcome variable is Daily cigarette smoking amounts, referring to the number of the cigarettes smoked per day at the time of the survey.

\section{Change in depression status}

The main independent variable is change in depression status, which was measured by the 11-item version of the Center for Epidemiologic Studies Depression Scale (CESD-11). The CESD-11 is a shorter version of the original 20-item version, and is a self-reported screening tool which is well validated [15]. The total score of the CESD11 was calculated by adding the scores for all 11 questions and multiplying these values by $20 / 11$ to meet the total sum of the original form. Scores of 16 and higher were considered evidence of likely depressed status [15-17].

Depression status changing was measured as change in depression status in a previous year and the subsequent year. We categorised them into four groups: No $\rightarrow$ No (persistence of no depression status), No $\rightarrow$ Yes (newly being in depression status), Yes $\rightarrow$ No (exiting from depression status), and Yes $\rightarrow$ Yes (persistence of depression status).

\section{Covariates}

Demographic, socioeconomic and health-related factors were included (S.Table 1). Demographic variables included sex, age, and region. Socioeconomic variables included education level, marital status, and income level (quartile). The sum of income reported by the household members was assigned to all of them as the household income. In the present study, we divided individuals into 
quartile using their equivalized household income, which considers the square root of the number of household members. Health-related factors included age at smoking commencement, alcohol consumption, and the absence or presence of chronic disease.

\section{Statistical analysis}

We calculated the distribution of the general characteristics at baseline. An analysis of variance (ANOVA) test was used to analyze the mean DCA at the first time point, for change of depression status categories. To analyze the effect of change of depression status on DCA, we used the generalized estimating equation (GEE) model. The GEE model is a more efficient and unbiased regression estimate for analysing longitudinal or repeated measures in research designs with nonnormal response variables [16]. We evaluated whether the DCA in each subsequent year was increased after depression status transitions over two consecutive years. Statistical analyses were performed using the GENMOD procedure in SAS version 9.4 (SAS Institute, Inc., Cary, $\mathrm{NC}$, USA). The results were considered statically significant if the $p$-value was less than 0.05 .

\section{Results}

Table 1 presents the general characteristics at the first change time point $(2008 \rightarrow 2009)$. Of the 1821 participants, $86.9 \%$ of males and $64.2 \%$ of females were in the No $\rightarrow$ No group. The Yes $\rightarrow$ Yes group was the smallest, accounting for $2.7 \%$ of males and $10.2 \%$ of females. Among males, the $\mathrm{No} \rightarrow$ Yes group had the highest mean DCA (18.6, SD: 9.88), and the Yes $\rightarrow$ No group had the smallest (16.40, SD: 6.29). Among females, the Yes $\rightarrow$ No group had the highest mean (13.95, SD: 8.48) DCA, and the No $\rightarrow$ No had the smallest (10.54, SD: 6.15). The mean ages at smoking initiation were 20.20 (SD: 4.44) in male and 32.54 (SD: 11.61) in female.

Table 2 indicated the results of the GEE model analysis of factors associated with DCA. The Yes $\rightarrow$ No male depression status group was the only one that showed a statistically significant decrease in DCA $(\beta=-0.631, p$ value $=0.0248$ ). Male participants who started smoking before 19 years old experienced greater DCA $(\beta=0.477$, $p$-value $=0.0290)$ than those who began at 19 or later. Increased DCA was observed among male participants who were $30-59$ years old $(30-39: \beta=1.728 ; 40-49$ : $\beta=$ 2.280;50-59: $\beta=2.211$ ), had a lower education level (middle school or under: $\beta=1.530$; high school: $\beta=$ 1.454), and consumed alcohol $2-3$ times a week $(\beta=$ $0.434)$. The low and low-middle income level group had decreased DCA (low: $\beta=-1.156$; low-mid: $\beta=-0.518$ ) compared to those with high income level. Among female participants, increased DCA was observed in individuals who were $50-59$ years old $(\beta=3.164)$ and consumed alcohol 2-3 times a week $(\beta=1.516)$.

Table 3 outlines the analysis, gradually narrowing subjects down to those with $\geq 20$ DCA. Among those with $\geq 10$ DCA, male in the Yes $\rightarrow$ No group had lower DCA $(\beta=-0.556)$ than those in the No $\rightarrow$ No group, which is similar to Table 2. Among those with $\geq 15$ DCA, males in the No $\rightarrow$ Yes group had higher DCA $(\beta=0.789)$ than the $\mathrm{No} \rightarrow$ No group. Analogously, males in the $\mathrm{No} \rightarrow \mathrm{Yes}$ category had higher DCA $(\beta=0.997)$ than the $\mathrm{No} \rightarrow \mathrm{No}$ group among participants with $\mathrm{a} \geq 20$ DCA. Among these, only the results for $\geq 20$ DCA was statistically significant.

Table 4 outlines the subgroup analysis regarding the effects of change of depression status on DCA, according to age at the smoking initiation. The male $\mathrm{Yes} \rightarrow \mathrm{No}$ group who initiated smoking before 19 had lower DCA $(\beta=-0.881)$ than the male No $\rightarrow$ No group who initiated smoking before 19. Similarly, the Yes $\rightarrow$ No male group members living with spouses had lower DCA $(\beta=-$ 1.088) than the No $\rightarrow$ No ones, although these are only statistically significant result in this analysis.

\section{Discussion}

This study examined the effect of smokers' depression status change on their daily cigarette smoking amount (DCA). Findings suggest that emerging from a depressed status is related to a decreased DCA among males. For males who smoke more than 20 cigarettes per day, depression status appears to increase DCA. Among males who began smoking before age 19, and males living with spouses, Yes $\rightarrow$ No depression status groups had a lower DCA than the $\mathrm{No} \rightarrow$ No groups.

Smokers experiencing significant depression are more likely to begin smoking, due to the antidepressant effect of nicotine. In addition, nicotine boosts bioavailability of serotonin, whose mechanism is similar to some antidepressants [18]. Another possible explanation about the relationship between changing depression status and smoking is individuals' socioeconomic status. It is clear that low socioeconomic status results in depression. Poverty and earning below the poverty threshold is associated with depression [19]. Also, there is a strong link between poverty and smoking. Individuals exiting poverty are more likely to quit smoking, and individuals whose living were below the poverty threshold is more likely to continue smoking $[20,21]$. Not only the individual level socioeconomic status but also the neighbourhood poverty which is area level socioeconomic status was a risk factor for increased smoking prevalence among 30-39 aged adult participants in Seattle [22]. The association of socioeconomic status with depression status and consistent smoking may be associated with our finding. Hence, depression contributes to increased 
Table 1 General characteristics at the first change time point (2008 $\rightarrow$ 2009)

\begin{tabular}{|c|c|c|c|c|c|c|c|c|c|c|c|c|}
\hline \multirow[t]{3}{*}{ Variables } & \multicolumn{12}{|c|}{ Daily cigarette smoking amount (DCA) } \\
\hline & \multicolumn{5}{|l|}{ Male } & \multirow{2}{*}{$\begin{array}{l}P \\
\text { value }\end{array}$} & \multicolumn{5}{|c|}{ Female } & \multirow{2}{*}{$\begin{array}{l}P \\
\text { value }\end{array}$} \\
\hline & $\mathrm{N}$ & $\%$ & MEANS & \pm & SD & & $\mathrm{N}$ & $\%$ & MEANS & \pm & SD & \\
\hline TOTAL & 1645 & 100 & 17.74 & \pm & 8.30 & & 176 & 100 & 11.32 & \pm & 6.72 & \\
\hline \multicolumn{13}{|c|}{ Change of depression status (2008 $\rightarrow 2009$ ) } \\
\hline $\mathrm{No} \rightarrow \mathrm{No}$ & 1429 & 86.9 & 17.80 & \pm & 8.34 & 0.2428 & 113 & 64.2 & 10.54 & \pm & 6.15 & 0.0764 \\
\hline No $\rightarrow$ Yes & 82 & 5.0 & 18.60 & \pm & 9.88 & & 26 & 14.8 & 11.15 & \pm & 6.73 & \\
\hline $\mathrm{Yes} \rightarrow \mathrm{No}$ & 90 & 5.5 & 16.40 & \pm & 6.29 & & 19 & 10.8 & 13.95 & \pm & 8.48 & \\
\hline Yes $\rightarrow$ Yes & 44 & 2.7 & 16.82 & \pm & 7.30 & & 18 & 10.2 & 13.67 & \pm & 7.44 & \\
\hline \multicolumn{13}{|c|}{ Age at the smoking initiation (years) } \\
\hline Under than 19 & 529 & 32.2 & 19.11 & \pm & 8.82 & $<.0001$ & 19 & 10.8 & 8.11 & \pm & 4.92 & 0.2523 \\
\hline 19 or older & 1116 & 67.8 & 17.09 & \pm & 7.96 & & 157 & 89.2 & 11.71 & \pm & 6.82 & \\
\hline \multicolumn{13}{|l|}{ Age (years) } \\
\hline $19-29$ & 150 & 9.1 & 15.03 & \pm & 6.31 & $<.0001$ & 10 & 5.7 & 7.00 & \pm & 2.87 & 0.0671 \\
\hline $30-39$ & 421 & 25.6 & 17.71 & \pm & 7.84 & & 10 & 5.7 & 9.00 & \pm & 6.62 & \\
\hline $40-49$ & 383 & 23.3 & 19.77 & \pm & 8.45 & & 24 & 13.6 & 11.46 & \pm & 6.21 & \\
\hline $50-59$ & 279 & 17.0 & 19.36 & \pm & 8.90 & & 26 & 14.8 & 12.88 & \pm & 7.94 & \\
\hline $60-69$ & 238 & 14.5 & 17.04 & \pm & 8.52 & & 30 & 17.0 & 13.57 & \pm & 7.31 & \\
\hline$\geq 70$ & 174 & 10.6 & 14.01 & \pm & 7.24 & & 76 & 43.2 & 10.72 & \pm & 6.27 & \\
\hline \multicolumn{13}{|l|}{ Region } \\
\hline Metropolitan & 669 & 40.7 & 17.39 & \pm & 7.92 & 0.0186 & 76 & 43.2 & 11.12 & \pm & 6.91 & 0.3972 \\
\hline Rural & 976 & 59.3 & 17.97 & \pm & 8.55 & & 100 & 56.8 & 11.47 & \pm & 6.61 & \\
\hline \multicolumn{13}{|l|}{ Education level } \\
\hline Middle school or under & 587 & 35.7 & 17.64 & \pm & 8.12 & 0.0172 & 134 & 76.1 & 11.51 & \pm & 6.24 & 0.4203 \\
\hline High school & 846 & 51.4 & 18.17 & \pm & 8.54 & & 33 & 18.8 & 11.18 & \pm & 6.91 & \\
\hline College or above & 212 & 12.9 & 16.28 & \pm & 7.68 & & 9 & 5.1 & 9.00 & \pm & 12.04 & \\
\hline \multicolumn{13}{|l|}{ Marriage status } \\
\hline Living w spouse & 1165 & 70.8 & 18.02 & \pm & 8.35 & 0.2954 & 40 & 22.7 & 10.08 & \pm & 5.44 & 0.0532 \\
\hline Living w/o spouse & 480 & 29.2 & 17.04 & \pm & 8.15 & & 136 & 77.3 & 11.68 & \pm & 7.03 & \\
\hline \multicolumn{13}{|l|}{ Income level } \\
\hline Low & 405 & 24.6 & 16.45 & \pm & 7.67 & 0.0238 & 70 & 39.8 & 11.50 & \pm & 6.52 & 0.4305 \\
\hline Lower middle & 446 & 27.1 & 18.30 & \pm & 7.99 & & 47 & 26.7 & 12.89 & \pm & 7.36 & \\
\hline Upper middle & 428 & 26.0 & 17.81 & \pm & 8.11 & & 38 & 21.6 & 10.03 & \pm & 6.06 & \\
\hline High & 366 & 22.2 & 18.38 & \pm & 9.38 & & 21 & 11.9 & 9.52 & \pm & 6.61 & \\
\hline \multicolumn{13}{|l|}{ Alcohol consumption } \\
\hline Non-drinkers & 311 & 18.9 & 17.77 & \pm & 7.61 & 0.0003 & 91 & 51.7 & 12.30 & \pm & 7.13 & 0.6671 \\
\hline Once a week or less & 594 & 36.1 & 17.33 & \pm & 8.01 & & 60 & 34.1 & 10.52 & \pm & 6.48 & \\
\hline 2-3 times a week & 408 & 24.8 & 17.03 & \pm & 7.97 & & 14 & 8.0 & 9.93 & \pm & 4.92 & \\
\hline More than 4 times a week & 332 & 20.2 & 19.31 & \pm & 9.57 & & 11 & 6.3 & 9.36 & \pm & 5.95 & \\
\hline \multicolumn{13}{|l|}{ Chronic diseases } \\
\hline No & 976 & 59.3 & 17.98 & \pm & 8.24 & 0.5129 & 53 & 30.1 & 10.23 & \pm & 6.19 & 0.7133 \\
\hline Yes & 669 & 40.7 & 17.38 & \pm & 8.39 & & 123 & 69.9 & 11.79 & \pm & 6.91 & \\
\hline
\end{tabular}


Table 2 The results of the generalized estimating equation analysis of factors associated with daily smoking amount

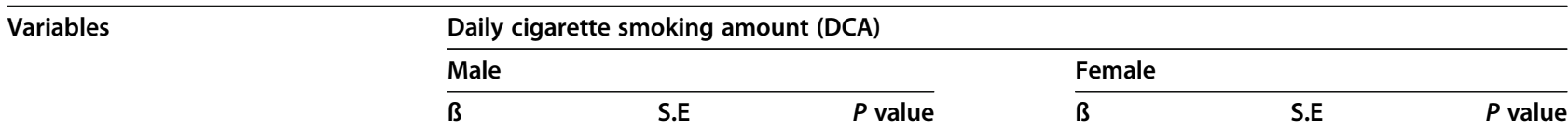

\section{Change of depression status}

$$
\begin{aligned}
& \mathrm{No} \rightarrow \mathrm{No} \\
& \mathrm{No} \rightarrow \mathrm{Yes} \\
& \mathrm{Yes} \rightarrow \mathrm{No}
\end{aligned}
$$$$
\text { Yes } \rightarrow \text { Yes }
$$

Ref.

0.414

$-0.631$

$-0.005$

Age at the smoking initiation (years)

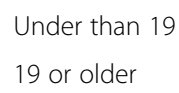

0.477

Ref.

0.219

0.338

0.281

0.578

$P$ value

B

Ref.

Age (years)

$19-29$
$30-39$
$40-49$
$50-59$
$60-69$
$\geq 70$

Region

Metropolitan

Rural

Education level

Middle school or under

High school

College or above

\section{Ref.}

1.728

2.280

2.211

0.880

$-1.377$

0.302

$<.0001$

0.344

$<.0001$

0.396

0.472

0.513

$<.0001$

0.0620

0.0073

Ref.

0.415

0.249

0.0956

0.448

0.0006

0.332

1.454

$<.0001$

Marriage status

\section{Living w spouse}

Living w/o spouse

Income level

$$
\begin{aligned}
& \text { Low } \\
& \text { Lower middle } \\
& \text { Upper middle } \\
& \text { High }
\end{aligned}
$$

Ref.

Ref.

$-0.126$

0.243

0.223

0.194

0.172

$-0.249$

Ref.

\section{Alcohol consumption}

Non-drinkers
Once a week or less
2-3 times a week
More than 4 times a week

Ref.

$-0.089$

0.434

0.197

0.220

1.972

0.252

Ref.

$-0.272$

0.142

0.0547

0.6515

0.0485

$<.0001$

$<.0001$

0.0075

0.1483

Chronic diseases

$$
\begin{aligned}
& \text { No } \\
& \text { Yes } \\
& \text { Year }
\end{aligned}
$$

$$
\begin{aligned}
& 2009 \\
& 2010
\end{aligned}
$$$$
2011
$$

Ref.

$-0.243$

$-0.454$
0.186

0.196
$-0.134$

$-0.065$

$-0.769$

$-0.009$

Ref.

Ref.

0.144

1.423

0.9196

1.591

1.312

0.2253

3.164

1.438

0.0278

2.414

1.375

0.0792

2.207

1.458

0.1301

Ref.

$-0.342$

0.524

0.5136

0.041

1.833

0.9822

0.827

1.652

0.6164

Ref.

Ref.

0.115

0.514

0.8228

$-1.167$

0.599

0.0514

$-0.314$

0.601

0.6008

$-0.418$

0.536

0.4348

Ref.

Ref.

0.371

0.468

0.4286

1.516

0.568

0.0076

2.080

0.676

0.0021

Ref.

$-0.200$

0.352

0.5696

Ref.

$-0.238$

0.495

0.6303

$-0.195$

0.512

0.7029 
Table 2 The results of the generalized estimating equation analysis of factors associated with daily smoking amount (Continued)

\begin{tabular}{|c|c|c|c|c|c|c|}
\hline \multirow[t]{3}{*}{ Variables } & \multicolumn{6}{|c|}{ Daily cigarette smoking amount (DCA) } \\
\hline & \multicolumn{3}{|l|}{ Male } & \multicolumn{3}{|l|}{ Female } \\
\hline & $B$ & S.E & $P$ value & $B$ & S.E & $P$ value \\
\hline 2012 & -1.389 & 0.255 & $<.0001$ & -0.399 & 0.986 & 0.6854 \\
\hline 2013 & -1.552 & 0.269 & $<.0001$ & -0.779 & 1.080 & 0.4706 \\
\hline 2014 & -1.779 & 0.278 & $<.0001$ & -1.039 & 1.011 & 0.3042 \\
\hline 2015 & -2.991 & 0.287 & $<.0001$ & -1.696 & 1.073 & 0.1137 \\
\hline 2016 & -2.908 & 0.281 & $<.0001$ & -1.865 & 1.097 & 0.0889 \\
\hline 2017 & -2.870 & 0.288 & $<.0001$ & -1.920 & 1.076 & 0.0743 \\
\hline 2018 & -2.795 & 0.301 & $<.0001$ & -1.252 & 1.067 & 0.2405 \\
\hline
\end{tabular}

DCA. Moreover, depression encourages smokers, particularly those who smoke more than 20 cigarettes per a day, to persist in this behaviour despite the health risk. It is, therefore, necessary to help smokers seek alternative, healthier antidepressant resources, or assistance to weather a financial crisis, or to encourage smokers with depressive symptoms to consult mental problem professionals.

Much like smoking from an early age was associated with increased DCA, several studies reported the association between the age of smoking initiation and smoking cessation as well as strong nicotine dependence [23-25]. Indeed, a study focused on smokers who visited the

Table 3 The results of the generalized estimating equation analysis among smokers with more than 10 or 20 daily smoking amount

\begin{tabular}{|c|c|c|c|c|c|c|}
\hline \multirow{3}{*}{$\begin{array}{l}\text { Change of } \\
\text { depression } \\
\text { status }\end{array}$} & \multicolumn{6}{|c|}{ Daily cigarette smoking amount (DCA) } \\
\hline & \multicolumn{3}{|c|}{ Male } & \multicolumn{3}{|c|}{ Female } \\
\hline & B* $^{*}$ & S.E & $P$ value & B* $^{*}$ & S.E & $P$ value \\
\hline
\end{tabular}

Among smokers with $\geq 10$ daily amount

\begin{tabular}{lllllll} 
No $\rightarrow$ No & Ref. & \multicolumn{5}{c}{ Ref. } \\
No $\rightarrow$ Yes & 0.453 & 0.363 & 0.2119 & 0.005 & 0.491 & 0.9914 \\
Yes $\rightarrow$ No & -0.556 & 0.300 & 0.0637 & 0.031 & 0.572 & 0.9570 \\
Yes $\rightarrow$ Yes & 0.768 & 0.619 & 0.2144 & -0.712 & 0.681 & 0.2963
\end{tabular}

Among smokers with $\geq \mathbf{1 5}$ daily amount

\begin{tabular}{lllllll} 
No $\rightarrow$ No & Ref. & \multicolumn{5}{c}{ Ref. } \\
No $\rightarrow$ Yes & 0.789 & 0.407 & 0.0526 & -0.133 & 0.512 & 0.7953 \\
Yes $\rightarrow$ No & -0.280 & 0.295 & 0.3427 & 0.869 & 0.578 & 0.1327 \\
Yes $\rightarrow$ Yes & 0.295 & 0.654 & 0.6520 & 0.854 & 0.669 & 0.2015
\end{tabular}

Among smokers with $\geq \mathbf{2 0}$ daily amount

\begin{tabular}{lllllll} 
No $\rightarrow$ No & Ref. & \multicolumn{5}{c}{ Ref. } \\
No $\rightarrow$ Yes & 0.997 & 0.416 & 0.0164 & -0.463 & 0.455 & 0.3090 \\
Yes $\rightarrow$ No & -0.360 & 0.301 & 0.2314 & 0.237 & 0.591 & 0.6889 \\
Yes $\rightarrow$ Yes & 0.335 & 0.667 & 0.6158 & 0.876 & 0.654 & 0.1805 \\
\hline
\end{tabular}

* Age, region, marital status, educational level, income level, chronic disease, alcohol consumption, and survey year were adjusted
Center for Cancer Prevention and Early Detection (in Korea's National Cancer Center) reported that nicotine dependence was much higher among those who started smoking aged 19 or earlier (compared to those who started aged 25 or later) [26]. Of significance in our study is the fact that male smokers who started before 19 years of age had a significantly increased DCA than those started later. Also, smokers who began before 19 years of age and changed from depressed to nondepressed status had a much lower DCA than general smokers with the same change pattern. This may provide evidentiary support for the implementation of smoking cessation programs by detecting depression symptoms and encourage to participating in antidepressant programs in parallel with smoking cessation programs for smokers with early initiation age.

This study demonstrated no statistically significant results among females. This is likely related to the low self-reporting rate among female smokers in Korea. This small number of female smokers in this study data might be underestimated by self-reported responses. The notion of an underestimation issue in this demographic is supported by the Korea National Health and Nutrition Examination Survey (KNHANES) study. By comparing the number of females who self-reported as smokers with the number confirmed to be through urine cotinine examination, a significant discrepancy between the prevalence of self-reported and biochemically-verified female smokers [27]. To identify the effect depression status change on female smokers, further study is needed, using data obtained from other smoking detection methods, e.g. urine cotinine examination.

This study has several limitations. First, since the KoWePS largely represents low income households, study findings are somewhat limited when it comes to generalizing to the national population, and high income households in particular. Second, because of data limitations, the analysis could not include clinical laboratory results (such as those from urinary cotinine level exams) that show the degree of smoking intensity. Third, the 
Table 4 Subgroup analysis of daily smoking amount stratified by age at the smoking initiation

\begin{tabular}{|c|c|c|c|c|c|c|c|c|c|c|}
\hline \multirow[t]{3}{*}{ Variables } & \multicolumn{10}{|c|}{ Daily cigarette smoking amount (DCA) } \\
\hline & \multirow{2}{*}{$\begin{array}{l}\text { No } \rightarrow \text { No } \\
\beta^{*}\end{array}$} & \multicolumn{3}{|c|}{ No $\rightarrow$ Yes } & \multicolumn{3}{|c|}{ Yes $\rightarrow$ No } & \multicolumn{3}{|c|}{ Yes $\rightarrow$ Yes } \\
\hline & & $\beta^{*}$ & S. E & $P$ value & $\beta^{*}$ & S. E & $P$ value & $B^{*}$ & S. E & $P$ value \\
\hline \multicolumn{11}{|l|}{ Male } \\
\hline \multicolumn{11}{|c|}{ Age at the smoking initiation (years) } \\
\hline Under than 19 & Ref. & 0.163 & 0.395 & 0.6799 & -0.881 & 0.337 & 0.0089 & -0.357 & 0.710 & 0.6151 \\
\hline 19 or older & Ref. & 0.166 & 0.702 & 0.8132 & -0.111 & 0.519 & 0.8301 & -0.022 & 0.966 & 0.9815 \\
\hline \multicolumn{11}{|l|}{ Female } \\
\hline \multicolumn{11}{|c|}{ Age at the smoking initiation (years) } \\
\hline Under than 19 & Ref. & -0.245 & 0.508 & 0.6294 & 0.196 & 0.664 & 0.7677 & -0.458 & 0.709 & 0.5183 \\
\hline 19 or older & Ref. & 0.756 & 0.810 & 0.3503 & 0.131 & 0.862 & 0.8795 & -0.107 & 0.979 & 0.9126 \\
\hline
\end{tabular}

use of self-reported responses means that measurement issues such as reporting bias and recall bias may have confounded the findings.

Despite the limitations, the present study has several strengths. First, we used data from a nationwide survey with randomly sampled longitudinal data and a 10-year follow up. As the KoWePS largely represents low income households, it can be generalized to South Korea's lowincome population. Second, previous studies have examined the association between depression and smoking cessation success. However, this study used a lagged GEE model to determine the ability of depression status change (which may occur through treatment) to lessen daily smoking cigarettes among smokers.

\section{Conclusions}

In conclusion, this study examined the effect depression status change on smokers' DCA. We found that change from depressed to non-depressed and non-depressed to depressed status is associated with decreasing and increasing DCA, respectively. Among those who began smoking before age 19, the subgroup that changed from depressed to non-depressed status had a much lower DCA than general smokers with the same change pattern. These findings may support the incorporation of depressive symptom treatment into smoking cessation programs.

\section{Abbreviations \\ DCA: Daily cigarette smoking amount; KoWePS: Korea Welfare Panel Study; CESD-11: An 11-item version of the center for epidemiologic studies depres- sion scale; ANOVA: Analysis of variance; GEE: Generalized estimating equation; KNHANES: Korea National Health and Nutrition Examination Survey; SD: Standard deviation; SE: Standard error}

\section{Supplementary Information}

The online version contains supplementary material available at https://doi. org/10.1186/s12889-021-11362-y.

Additional file 1.

\section{Acknowledgements}

Not applicable.

Authors' contributions

SHK, WJJ, SIJ, and ECP designed the study and contributed to the discussion. SHK carried out the statistical analysis and drafted and revised the manuscript. All authors read and approved the final manuscript.

\section{Funding}

This research received no specific grant from any funding agency in the public, commercial or not-for-profit sectors.

Availability of data and materials

The KoWePS data supporting this article is openly published and provided for the research study by the Korean government. The data is openly available in https://www.koweps.re.kr:442/main.do by submitting oath and data utilization plan

\section{Declarations}

Ethics approval and consent to participate

This study was approved by the Institutional Review Board of Korea Institute for Health and Social Affairs (No. 2021-002). This data is publicly accessible and written informed consent is obtained from all the participants before participating in the survey. Respondents' information was completely anonymized for use for research purposes and unidentified prior to analysis. The authors assert that all procedures contributing to this work comply with the ethical standards of the relevant national and institutional committees on human experimentation and with the Helsinki Declaration of 1975, as revised in 2000 .

Consent for publication

Not applicable.

Competing interests

The authors declare that they have no competing interests.

Author details

'Department of Public Health, Graduate School, Yonsei University, Seoul, Republic of Korea. ${ }^{2}$ Institute of Health Services Research, Yonsei University, Seoul, Republic of Korea. ${ }^{3}$ Department of Preventive Medicine, Yonsei University College of Medicine, 50 Yonsei-ro, Seodaemun-gu, Seoul 03722, Republic of Korea. 
Received: 14 August 2020 Accepted: 24 June 2021

Published online: 03 July 2021

\section{References}

1. Heo $\mathrm{S}$, Lee J-T. Disease burdens from environmental tobacco smoke in Korean adults. Int J Environ Health Res. 2015;25(3):330-48. https://doi.org/1 0.1080/09603123.2014.945513.

2. Kim I-S. Present situation and direction of antismoking policies in Korea. J Korean Med Assoc. 2014;57(12):978-80. https://doi.org/10.5124/jkma.2014. 57.12 .978

3. Glassman AH, Helzer JE, Covey LS, Cottler LB, Stetner F, Tipp JE, et al. Smoking, smoking cessation, and major depression. J Am Med Assoc. 1990; 264(12):1546-9. https://doi.org/10.1001/jama.1990.03450120058029.

4. Covey LS, Glassman AH, Stetner F. Depression and depressive symptoms in smoking cessation. Compr Psychiatry. 1990;31(4):350-4. https://doi.org/10.1 016/0010-440X(90)90042-0.

5. Levine MD, Marcus MD, Perkins KA. A history of depression and smoking cessation outcomes among women concerned about post-cessation weight gain. Nicotine Tob Res. 2003;5(1):69-76. https://doi.org/10.1080/14 62220021000060455

6. Hall SM, Muñoz RF, Reus VI, Sees KL. Nicotine, negative affect, and depression. J Consult Clin Psychol. 1993;61(5):761-7. https://doi.org/10.1037/ 0022-006X.61.5.761.

7. Dalack GW, Glassman AH, Rivelli S, Covey L, Stetner F. Mood, major depression, and fluoxetine response in cigarette smokers. Am J Psychiatry. 1995:152(3):398-403. https://doi.org/10.1176/ajp.152.3.398.

8. Glassman AH, Covey LS, Stetner F, Rivelli S. Smoking cessation and the course of major depression: a follow-up study. Lancet. 2001;357(9272):1929_ 32. https://doi.org/10.1016/S0140-6736(00)05064-9.

9. Tsoh JY, et al. Development of major depression after treatment for smoking cessation. Am J Psychiatry. 2000;157(3):368-74.

10. Perkins KA, Jao NC, Karelitz JL. Consistency of daily cigarette smoking amount in dependent adults. Psychol Addict Behav. 2013;27(3):723-9. https://doi.org/10.1037/a0030287.

11. Alpert HR, Connolly GN, Biener L. A prospective cohort study challenging the effectiveness of population-based medical intervention for smoking cessation. Tob Control. 2013;22(1):32-7. https://doi.org/10.1136/toba ccocontrol-2011-050129.

12. Augustson EM, Marcus SE. Use of the current population survey to characterize subpopulations of continued smokers: a national perspective on the "hardcore" smoker phenomenon. Nicotine Tob Res. 2004;6(4):621-9. https://doi.org/10.1080/14622200410001727876.

13. Hymowitz N, Cummings K, Hyland A, Lynn W, Pechacek T, Hartwell T. Predictors of smoking cessation in a cohort of adult smokers followed for five years. Tob Control. 1997;6(suppl 2):S57-62. https://doi.org/10.1136/tc.6. suppl_2.S57.

14. Hyland A, Levy DT, Rezaishiraz H, Hughes JR, Bauer JE, Giovino GA, et al. Reduction in amount smoked predicts future cessation. Psychol Addict Behav. 2005;19(2):221-5. https://doi.org/10.1037/0893-164X.19.2.221.

15. Kohout FJ, Berkman LF, Evans DA, Cornoni-Huntley J. Two shorter forms of the CES-D depression symptoms index. J Aging Health. 1993;5(2):179-93. https://doi.org/10.1177/089826439300500202.

16. Kim S, Jeong W, Jang BN, Park EC, Jang SI. Associations between substandard housing and depression: insights from the Korea welfare panel study. BMC Psychiatry. 2021;21(1):12. https://doi.org/10.1186/s12888-020-03 011-2.

17. Comstock GW, Helsing KJ. Symptoms of depression in two communities Psychol Med. 1977;6(4):551-63. https://doi.org/10.1017/S0033291700018171.

18. Schnoll RA, Lerman C. Current and emerging pharmacotherapies for treating tobacco dependence. Expert Opin Emerg Drugs. 2006;11(3):429-44. https://doi.org/10.1517/14728214.11.3.429.

19. Heflin CM, Iceland J. Poverty, material hardship, and depression*. Poverty. 2009;90(5):1051-71. https://doi.org/10.1111/j.1540-6237.2009.00645.x.

20. Flint AJ, Novotny TE. Poverty status and cigarette smoking prevalence and cessation in the United States, 1983-1993: the independent risk of being poor. Tob Control. 1997;6(1):14-8. https://doi.org/10.1136/tc.6.1.14.

21. Yoimg-Hoon K-N. A longitudinal study on the impact of income change and poverty on smoking cessation. Can J Health. 2012;103(3):189-94. https://doi.org/10.1007/BF03403811.

22. Cambron C, Kosterman R, Hawkins JD. Neighborhood poverty increases risk for cigarette smoking from age 30 to 39. Ann Behav Med. 2018;53(9):858-64.
23. Khuder SA, Dayal HH, Mutgi AB. Age at smoking onset and its effect on smoking cessation. Addict Behav. 1999;24(5):673-7. https://doi.org/10.1016/ S0306-4603(98)00113-0.

24. Everett SA, Warren CW, Sharp D, Kann L, Husten CG, Crossett LS. Initiation of cigarette smoking and subsequent smoking behavior among US high school students. Prev Med. 1999;29(5):327-33. https://doi.org/10.1006/ pmed.1999.0560.

25. Breslau N, Fenn N, Peterson EL. Early smoking initiation and nicotine dependence in a cohort of young adults. Drug Alcohol Depend. 1993;33(2): 129-37. https://doi.org/10.1016/0376-8716(93)90054-T.

26. Park SM, Son KY, Lee YJ, Lee HCS, Kang JH, Lee YJ, et al. A preliminary investigation of early smoking initiation and nicotine dependence in Korean adults. Drug Alcohol Depend. 2004;74(2):197-203. https://doi.org/10.1016/j. drugalcdep.2004.01.001.

27. Kang HG, Kwon KH, Lee IW, Jung B, Park EC, Jang SI. Biochemically-verified smoking rate trends and factors associated with inaccurate self-reporting of smoking habits in Korean women. Asian Pac J Cancer Prev. 2013;14(11): 6807-12. https://doi.org/10.7314/APJCP.2013.14.11.6807.

\section{Publisher's Note}

Springer Nature remains neutral with regard to jurisdictional claims in published maps and institutional affiliations.
Ready to submit your research? Choose BMC and benefit from:

- fast, convenient online submission

- thorough peer review by experienced researchers in your field

- rapid publication on acceptance

- support for research data, including large and complex data types

- gold Open Access which fosters wider collaboration and increased citations

- maximum visibility for your research: over $100 \mathrm{M}$ website views per year

At BMC, research is always in progress.

Learn more biomedcentral.com/submissions 